\title{
EL FACTOR TIEMPO EN EL EXORDIO DE BAYNA L-QASTRAYN
}

\author{
$\mathrm{M}^{\mathrm{a}}$ Dolores LÓPEZ ENAMORADO \\ Universidad de Sevilla
}

\begin{abstract}
A $\mathbf{M}^{\mathrm{a}}$ Jesús Rubiera
"Y perdone Dios al tiempo, al tiempo cuya mera existencia -que no se detiene ni un momento- es un engaño, y qué engaño, para el hombre! (...)

Una vez más, ique perdone Dios al tiempo!" ${ }^{1}$
\end{abstract}

\section{Introducción}

El mismo año en que se completaba la publicación de la Trilogta, 1957, su autor, Naŷib Mahfüz, afirmaba en una entrevista que el verdadero protagonista de esta obra es el tiempo ${ }^{2}$. Y en efecto, es ese elemento el que se erige como telón de fondo de esta importante novelarío, dirigiendo los destinos de sus personajes y los avatares de su historia.

El tiempo, junto con el espacio, son las dos coordenadas sobre las que se organiza el discurso narrativo. Ambas forman una unidad estructural que se denomina cronotropo, donde "se enlazan y desenlazan

${ }^{1}$ Monólogo del Sr. Ahmad 'Abd al-Ŷyawwād en al-Sukkariyya. Traducción castellana: E. Gálvez Vázquez, C. Gómez Camarero, M. D. López Enamorado y otros. La Azucarera. Barcelona: Alcor, 1990, p. 116.

${ }^{2}$ Entrevista publicada en Ajir Sã'a, 9.10.1957, p. 27; citada por Jomier, J., "La vie d'une famille au Caire d'après trois romans de M. Naguib Mahfuz". $M I D E O$, IV (1957), p. 84. 
los nudos argumentales. Se puede afirmar abiertamente que a ellos pertenece el papel principal en la formación del argumento" ${ }^{3}$. En este entramado espacio-temporal se insertan los hechos, los personajes y sus relaciones y es, en consecuencia, donde se desarrolla la acción de la obra. Quiero, no obstante, destacar el papel crucial que desempeña el tiempo sobre el espacio. Este último representa lo inmóvil, lo permanente y lo inmutable, mientras que el primero simboliza lo cambiante, lo variable, la evolución. Por tanto, el movimiento está asociado necesariamente al paso del tiempo. Siguiendo a Pozuelo, "todo discurso narrativo implica sucesión, movimiento, pero en el caso de la novela este rasgo se superlativiza porque la novela va íntimamente ligada a la temporalidad, tanto que la administración del tiempo es el eje de la narrativa"4.

La Trilogı́a, como novela realista y reflejo de la realidad, está sometida a esas coordenadas, que son las mismas en las que se desenvuelve la vida. Sin embargo, es imposible -salvo en ciertos experimentos narrativos- que el tiempo de la novela, de la ficción, siga y coincida de forma exacta con el tiempo exterior, el de la realidad. La cuestión radica en que ambos tiempos, el literario y el cronológico, son verdaderamente distintos, y como tales hay que verlos. Como apunta Bobes, "el tiempo cronológico es aséptico y acoge con la misma indiferencia una acción importante y otra insignificante; el tiempo literario se convierte en un signo que manifiesta el orden, la reiteración, la omisión, la importancia de las acciones, seleccionándolas y subrayándolas en coherencia con el conjunto. El tiempo as tratado tiene su lógica independiente del determinismo a que lleva la simple sucesión"s. De hecho, una novela que reflejara y narrara fielmente cada uno de los movimientos de sus personajes en todos y cada uno de los momentos y lugares sería prácticamente ilegible. Así, la elección de motivos ha de

3 Bajtin, Mijail. Teoría y estética de la novela. S.l.: Altea, Taurus, Alfaguara, 1989 , p. 400.

${ }^{4}$ Pozuelo Yvancos, J. M. Teoría del lenguaje literario. Madrid: Cátedra, 1992, p. 260.

5 Bobes Naves, M. C. Teoria general de la novela: Semiología de "La Regenta". Madrid: Gredos, 1985, p. 190. 
verse necesariamente sometida al espacio textual, más o menos reducido, de que dispone el autor para narrar su obra.

En este sentido, el escritor se enfrenta a dos planos: la Historia o Trama que quiere narrar ${ }^{6}$, y el orden temporal en el que él mismo dispone y presenta a su voluntad los acontecimientos, lo que sería el Discurso o Argumento?. Por tanto, y dado que la intervención del novelista es aquí fundamental, su utilización del tiempo será uno de los principales rasgos diferenciadores y específicos de su estilo. Bobes llega a apuntar que el arte de la novela es el arte del tiempo "porque es el arte que tiene mayores atribuciones sobre él: lo dilata, lo resume, lo orienta en el sentido progresivo o regresivo, altera su orden, vuelve a vivirlo, etc..." ${ }^{8}$. Se trata en definitiva de crear lo que Genette denomina un pseudotiempo, al que define como "un falso tiempo que equivale a uno verdadero"'.

Finalmente quiero apuntar que el creador de una novela realista no tiene tanta libertad a la hora de manipular el tiempo de su obra como sí la tienen novelistas de otras tendencias, que no se ven obligados a someterse a esa visión indeformada y veraz. La verosimilitud que la obra realista exige de su autor le impide así "traspasar el marco de la temporalidad vital humana, por lo que se refiere a la duración, es decir, tomados los personajes como personas, su tiempo es el de una persona"10. En la novela realista, por tanto, características como la inmortalidad o la ubicuidad, relacionadas con un tiempo y un espacio ficticios y/o distorsionados, serían imposibles. No obstante, y como veremos más adelante, el autor posee recursos para romper esa relación lineal y estricta entre la temporalidad de la ficción y la de la realidad,

6 Definida como el "conjunto de hechos narrativos en el orden cronológico en que se suceden". Bobes Naves, M. C. Op. cit., p. 23.

7 "Constituido por los mismos hechos [que la historia], en el orden y disposición en que el autor los da a conocer bajo unos signos linguísticos organizados para conseguir un sentido literario determinado". Ibid.

${ }^{8}$ Bobes Naves, M. C. Comentario semiológico de textos narrativos, Oviedo: Publicaciones de la Universidad, 1991, p. 179.

${ }^{9}$ Genette, G. Figuras III. Barcelona: Lumen, 1989, p. 90.

${ }^{10}$ Bobes Naves, M. C. La novela. Madrid: Síntesis, 1993, p. 173. 
entre ellos se encuentran procedimientos tales como los sueños ${ }^{11}$, los monólogos, los presentimientos, colocar un hecho en una posición privilegiada dentro del relato, adelantar o atrasar acontecimientos, ralentizar o acelerar determinadas descripciones, hacer referencias temporales internas, relacionar unos hechos con otros, repetir la narración de algunos momentos concretos, etc. Procedimientos que, como veremos, Naŷib Mahfüz conoce y utiliza con verdadera maestría.

\section{Elementos temporales en el exordio de Bayna l-Qașrayn}

\subsection{Metodología utilizada}

El tiempo es una unidad estructural de la novela, $y$ ha sido sometido a diversas metodologías de análisis defendidas por críticos adscritos a otras tantas escuelas y tendencias. Entre ellas y como base, emplearé aquí el esquema de análisis general propugnado por Gérard Genette $^{12}$, cuya metodología tiene, a mi modo de ver, un gran rendimiento operativo a la hora de atralizar los diversos fenómenos que se dan en la novela.

A propósito del factor tiempo, Genette establece dos tipos, de los cuales uno hace referencia al significado (el tiempo de la cosa contada o tiempo de la historia ${ }^{13}$ ) y otro al significante (el tiempo del relato o del discurso). Entre ambos se establece una serie de relaciones que este crítico clasifica en tanto en cuanto dan lugar a fenómenos temporales

11 Véase sobre este punto concreto el artículo de Salvador Peña, "Sueños de Mahfuz: lo onírico en la construcción de la novela", Anaquel de Estudios Árabes, 4 (1993), pp. 129-148.

12 Genette, G. Op. cit.

${ }^{13}$ En todos los casos sustituiré el têrmino "diégesis", empleado por Genette, por su acepción más moderna de "historia". Según Aristóteles, la diégesis es el relato puro, transmitido por el narrador, mientras que la mímesis es el relato recitado por los personajes. En su acepción actual, la diégesis es la historia: conjunto de los acontecimientos relatados, o contenido de un relato frente al significante de la narración. Véase: Marchese, A. y Forradellas, J. Diccionario de retórica, crítica y terminología literaria. Barcelona: Ariel, 1991. S.v. "diégesis" e "historia", pp. 102 y 199-200. 
concretos, y que son fundamentalmente tres: relaciones de orden, de duración y de frecuencia.

A este análisis añadiré uno de los puntos que Bobes plantea en su metodología, y que no ha sido considerado por Genette en sus trabajos: se trata del concepto de sucesividad/simultaneidad en la trayectoria vital de los personajes de la novela.

Partiendo de este esquema de trabajo, se identificarán las unidades temporales, por separado o en bloque, que conforman el exordio de Bayna l-Qașrayn, comentándolas y organizándolas en los apartados anteriormente expuestos. De esta forma quedarán desglosadas las unidades formales relacionadas con la temporalidad, y podrán servir de clara orientación acerca de los usos que un novelista, Naŷîb Maḥfūz, hace de la cronología a la hora de construir su obra.

\subsection{El exordio de Bayna l-Qaṣrayn}

El exordio o presentación de una novela posee unas características especiales frente al resto de la obra. En el caso de la Trilogta, se da el hecho evidente de que el lector, al iniciar la lectura de Bayna lQașrayn, no sabe absolutamente nada de lo que ha sucedido anteriormente, ya que la novela se inicia en un punto concreto de la historia y, de entrada, no existe el pasado previo a ella. En esa elección del momento de la historia en el que arranca el relato radica la primera e importante alternativa de su autor. Este tipo de comienzo es uno de los recursos tradicionales de la narrativa, y se completa normalmente con una vuelta atrás o analepsis a través de la cual el narrador aclara y explica diversos puntos, al objeto de que el lector pueda ir situando personajes, hechos y relaciones.

Esta oscilación presente-pasado-presente se da a lo largo de toda la Trilogla, pero es más característica en el inicio de las tres novelas que la componen, y de manera especial en el de Bayna l-Qasrayn, por ser el comienzo absoluto de la obra. En esta presentación el lector lo ignora todo sobre personajes, relaciones, etc., mientras que en las de Qaṣr alŠawq y al-Sukkariyya ya parte de un conocimiento previo, más o menos amplio, de ese pasado.

El bloque de capítulos que constituye la presentación de la obra es lo que se denomina exordio, aunque se utilizan otros términos como 
obertura, apertura, exposición, presentación, introducción, etc. ${ }^{14}$, que usaré indistintamente, si bien me decanto por el término clásico de exordio, cuya definición se incluye a continuación:

\begin{abstract}
"En la oratoria clásica, el exordio es la parte inicial del discurso en la que se busca, sobre todo, predisponer al auditorio hacia una benévola atención. (...) En sentido amplio, el exordio es el comienzo de una trama. (...) El exordio es también la apertura, muy variada, de una obra narrativa, en la que el escritor -0 el narrador, si es distinto al escritor-puede anticipar algunos temas o problemas o situaciones del desarrollo de la historia"15.
\end{abstract}

El exordio de Bayna l-Qasrayn tiene una estructura compleja. Se trata de un todo uniforme y diferenciado del resto de la obra, caracterizado por un movimiento de vaivén continuo entre el presente y el pasado, que es necesario para cumplir la función a la que está destinado. Y por otro lado, es fundamental para que el lector conozca los datos que lo introducirán paulatinamente en ese mundo desconocido del pasado previo al relato.

Partiendo de esas premisas, considero que el exordio de Bayna $l-$ Qaṣrayn se extiende a lo largo de los capítulos 1 al $15^{16}$. A través de

${ }^{14}$ Sizā Ahmad Qäsim, en su libro Binā' al-riwãya: dirãsa muqärana liTulatáiyya Nầib Mahfüz. [E] Cairo]: Al-Hay'a al-Mișriyya al-'Āmma li-l-Kitāb, 1984, pp. 30 y ss., traduce el concepto exordio por el término árabe iftităhiyya.

${ }^{15}$ Marchese, A. y Forradellas, J. Op. cit., s.v. "exordio", pp. 156-7.

${ }^{16}$ Qāsim, S. A. Op. cit., p. 34, habla de dos exposiciones diferentes, una fundamental, que comprendería los capítulos 1 al 15, y otra secundaria, correspondiente a los capítulos 16 a 26 de esta obra. En la segunda, se continuaría la presentación de los personajes y las relaciones entre ellos. Este crítico considera que los verdaderos acontecimientos se inician en el capítulo 27, cuando Amina hace su particular revolución saliendo de casa para visitar la mezquita de al-Husayn, lo que rompe con la cotidianeidad y supone un cambio radical en la construcción de la novela y, por tanto, de la temporalidad. No obstante, en mi trabajo sólo consideraré el exordio propiamente dicho, los capítulos 1 al 15 , porque en los siguientes, aunque en efecto continúa la presentación de personajes, ya se van narrando hechos no cotidianos que pueden considerarse dentro del argumento de la novela en su totalidad. Una segunda razón es la entidad que tiene este exordio de quince capítulos -la narración de 24 horas en la vida de la familiacomo unidad independiente y diferenciada del resto de la novela. 
los datos puntuales, unidos a la concatenación de hechos y a la relación que se establece entre estos capítulos, se deduce que el ámbito temporal en que se enmarcan es de 24 horas, es decir, un día completo en la vida de la familia 'Abd al-Ŷyawwād.

La situación horaria en la que éstos tienen lugar es dada a conocer por Naȳib Mahfüz a través de diversas referencias, de las que se pueden extraer los siguientes datos, ya sean puntuales o muy aproximados:

-Capítulo 1.- Medianoche. Aún no se sabe de qué mes ni de qué año. Amīna está esperando el regreso de su esposo a casa.

-Capítulo 2.- Continuación del anterior. Medianoche del día 10 al 11 de octubre de 1917, dato que conocemos a través de una referencia a la historia ${ }^{17}$.

-Capítulo 3.-El despertar de la familia 'Abd al-Ŷawwäd. Nada indica que haya transcurrido más de una noche entre este capítulo y el anterior, por tanto considero que se trata de la mañana siguiente, 11 de octubre de 1917.

-Capítulo 4.- El desayuno de los hombres y su salida de la casa para realizar sus tareas diarias (trabajo o estudio). La misma mañana del día 11.

-Capítulo 5.-El desayuno de las mujeres, a continuación de la partida de los hombres.

-Capítulo 6.- Las faenas domésticas de las mujeres tras el desayuno.

- Capítulo 7.- Cambio de escenario. El señor Ahmad en su tienda de al-Naḥ̣āsīn. Mañana del mismo día 11.

${ }^{17}$ Se trata del dato aportado en un diálogo entre Aminna y el señor, a través del cual el lector es informado de que la novela arranca el día que es nombrado sultán el príncipe Ahimad Fu'ād (10.10.1917), la jornada siguiente a la muerte de su antecesor en el cargo, el sultán Husayn Kämil. Mahfuz, Naguib. Entre dos Palacios (traducción al castellano de E. Gálvez Vázquez, R. Gil Grimau, M.D. López Enamorado y otros). Barcelona: Alcor, 1989, p. 16. En adelante citaré Mahfuz, N. E.P. 
-Capítulo 8.- El relato pasa de la mañana a la tarde sin detenerse en el almuerzo. Capítulo centrado en Kamāl y sus actividades a la salida de la escuela.

-Capítulo 9.- La reunión del café "antes de la puesta del sol" ${ }^{18}$.

-Capítulo 10.- Fahmî y Kamāl suben a la azotea de la casa. "El sol estaba próximo a ocultarse ${ }^{119}$. El capítulo finaliza al anochecer, cuando "perciben por vez primera la oscuridad que avanzaba por el horizonte" 20 .

-Capítulo 11.- Prolongación de la reunión del café, ya de noche, con las mujeres y Kamāl, hasta que la mayoría de los miembros de la familia se va a dormir.

-Capítulo 12.- Noche del mismo día 11. Yāsinn sale de casa y va a una taberna.

-Capítulo 13. - Continuación inmediata del anterior.

-Capítulo 14.- Retrocede un tanto la narración hacia el pasado para retomar las actividades del señor Ahmad en la tienda. No existe ninguna indicación que lleve a suponer que ha pasado una noche completa o más, por tanto me inclino a pensar que se trata del mismo día 11.

-Capítulo 15.- Continuación del anterior. Se inicia al anochecer, cuando el señor sale de su tienda para ir a la casa de la cantora a fin de concertar una fiesta que se celebrará al día siguiente. Nada sabemos de su regreso a casa, pero con éste se alcanzarían las 24 horas, un día completo, en la vida de los 'Abd al-Yawwād.

A continuación se analizará este exordio partiendo de la metodología mencionada más arriba.

\subsubsection{Las relaciones de orden}

"Estudiar el orden temporal de un relato es confrontar el orden de disposición de los acontecimientos o segmentos temporales en el discurso narrativo con el orden de sucesión de esos mismos aconteci-

\footnotetext{
${ }^{18}$ Mahfuz, N. E.P., p. 41.

${ }^{19}$ Ibid., p. 45.

${ }^{20}$ Ibid., p. 48 .
} 
mientos o segmentos temporales en la historia, en la medida en que va explícitamente indicado por el propio relato o se puede inferir de tal o cual indicio indirecto" 21 .

El exordio de Bayna l-Qasrayn no sigue una linealidad en la presentación de los hechos, quedando, por tanto, rota ésta a través de una serie de anacronías generadas por el autor. Esta ruptura del tiempo de la historia en el relato se dirige normalmente hacia el pasado, a través de una gran profusión de flash back o analepsis, referidos a cada uno de los personajes, a fin de que el lector, en una primera aproximación, pueda conocer una porción del pasado de éstos y entender parte de sus actitudes.

Podría hablarse en este exordio de una retrospección continua, ya que la analepsis constituye el elemento fundamental de la construcción del relato, más importante incluso que el relato primero. Por ese motivo, las analepsis de esta presentación serán comentadas en bloque, sin detenerme en las diferentes variantes propuestas por Genette.

La técnica más empleada por Naŷîb Maḥūz para plasmar esta vuelta atrás en el exordio de Bayna l-Qașrayn es el recurso a la memoria de los personajes, en el que el pensamiento de éstos fluye libremente, aportando al lector una serie de datos sobre su pasado, necesarios para iniciar la andadura de los protagonistas.

Determinadas situaciones u objetos pueden desencadenar ese flujo de pensamientos que se traducirá en la obra a través bien de monólogos, bien por medio del estilo indirecto libre. En el monólogo interior directo, el narrador no interviene como tal, sino que deja que éste pase automáticamente al relato. Es mucho menos frecuente en este exordio, y, como ejemplo, destaco el que protagoniza Yāsīn en su salida nocturna, a través del cual conocemos una parte de su pasado, junto con su situación afectiva contemporánea al momento del relato, y del que recojo a continuación algunos fragmentos:

"Quitate de la cabeza esos estúpidos pensamientos; a paseo la Escuela y el inspector, ¡maldita sea! (...) ¿Me reconocería si me viera? ¿Reconocería en

${ }^{21}$ Genette, G. Op. cit., p. 91. 
mí al niño que en aquel entonces había conocido como hijo de aquella mujer?" ${ }^{\text {22 }}$.

Mediante el estilo indirecto libre, mucho más abundante en este exordio, el narrador se sitúa en la mente del personaje y sigue el transcurso de su pensamiento, narrándolo él mismo a través de la reelaboración o de la presentación en tercera persona, o introduciéndolo con expresiones del tipo "recordó" y otras. Puede citarse como ejemplo el siguiente fragmento:

"Recordó, con el mismo placer con que siempre lo hacía, cómo un día que estaba sacudiendo la cortina por la ventana, echó un vistazo hacia la calle a través de ésta, que tenía una hoja abierta para sacudir el polvo, y se encontró con él, que la contemplaba con una mezcla de asombro y admiración $(\ldots)^{\prime 23}$.

La analepsis es también utilizada por el autor en la narración propiamente dicha, no ya a través de los monólogos, y como ejemplo de ello podemos destacar el capítulo 1, que tiene como protagonista a Amīna, esperando al señor en la celosía. En él, Nayīib Maḥūz da a conocer al lector a través de la analepsis algunos de los hechos que han ocurrido en la vida de este personaje desde su matrimonio, sus sentimientos ante ellos, así como las relaciones con su esposo.

\subsubsection{Las relaciones de duración}

"Se entiende por velocidad la relación entre una medida temporal y una medida espacial. (...) La velocidad del relato se definirá por la relación entre una duración ta de la historia- medida en segundos, minutos, horas, días, meses y años, y una longitud -la del texto-medida en líneas y en páginas" 24 .

Por tanto, a través de esta relación se descubrirá el ritmo, más rápido o más lento, del relato. Los cuatro recursos temporales son:

${ }^{22}$ Mahfuz, N. E.P., pp. 55 y 57.

${ }^{23}$ Ibid., p. 24.

${ }^{24}$ Genette, G. Op. cit., p. 145. 
pausa, escena, sumario y elipsis. Estos dan lugar a ritmos diferentes, cuya comparación con los cuatro movimientos musicales fundamentales me parece obvia.

-En la pausa, la longitud del relato es amplia, mientras que el tiempo de la historia se detiene. Ritmo muy lento, comparable, en el ámbito musical, a un adagio.

-La escena, la mayoría de las veces dialogada, presenta una igualdad convencional entre tiempo del relato y tiempo de la historia. Ritmo intermedio, asimilable a un andante.

-Un texto o fragmento en el que abunde el sumario se caracteriza por una longitud del relato moderadamente menor que el tiempo de la historia. Ritmo moderadamente rápido, equivalente a un allegro.

-En la elipsis el tiempo de la historia es muy amplio, mientras que la longitud del relato es cero, por hacer el texto un salto en el que los hechos ocurridos no se narran. Daría lugar a un ritmo muy rápido, que se corresponde en la nomenclatura musical al movimiento presto.

Por lo que se refiere al exordio de Bayna l-Qasrayn, y tras el análisis detallado de su estructura temporal, es obvio destacar que el uso frecuente de analepsis conlleva una serie de pausas descriptivas importantes, ya que se tiene que rellenar una elipsis constante, que es la referida al pasado de los personajes.

Estas pausas, en las que el tiempo de la historia se detiene, se alternan en este exordio con el relato sumario, en el que se narran en algunas páginas varios años de existencia de los personajes.

Por tanto, si tenemos en cuenta que esta presentación narra un solo día de la vida de la familia 'Abd al-Ŷawwād, concluiríamos que el ritmo es muy lento, equivalente a un adagio. Pero si consideramos que en realidad se está narrando una buena parte de la existencia anterior (25 años de matrimonio entre Amīna y el señor, por ejemplo), tendríamos que estimar que el ritmo es moderadamente rápido, ya que se condensa un pasado amplio en un número relativamente reducido de páginas. No obstante, y en este sentido, pienso que la alternancia entre las pausas descriptivas y el relato sumario de estos capítulos transmite una sensación de lentitud que no se halla en el resto de la novela.

Qāsim, en su estudio comparativo de la Trilogía, destaca esa alternancia entre la narración de una solo día y la rememoración de un 
pasado de 25 años, lo que considera como una característica que diferencia a esta obra de otras novelas realistas ${ }^{25}$.

\subsubsection{Las relaciones de frecuencia}

Estas relaciones hacen referencia a la capacidad del autor de narrar una o varias veces una determinada acción, o una serie de acciones repetidas. Siguiendo a Genette ${ }^{26}$, se establecen los siguientes tipos de frecuencia, que dan lugar a otros tantos tipos de relato:

-Relato singulativo, en el que se cuenta una vez lo que ha ocurrido una vez, o $n$ veces lo que ha ocurrido $n$ veces.

-Relato repetitivo, que narra $n$ veces lo que ha ocurrido una vez. Este recurso evidentemente resalta de manera contundente, a través de la reiteración, una acción determinada.

-Relato iterativo, en el que se cuenta una sola vez lo que ha ocurrido $n$ veces. Este tipo de relato reduce en buena medida la extensión del texto, y es introducido en la obra a través de fórmulas del tipo "todos los días", "todos los meses", etc...

El exordio de Bayna l-Qașrayn se caracteriza en su conjunto por ser un relato iterativo, en el que se cuenta una vez lo que ha ocurrido $n$ veces. El empleo que hace Mahfüz de este recurso transmite al lector una impresión de cotidianeidad que se plasma a través de expresiones como "cada noche", "todos los dfas", etc., que se encuentran a menudo a lo largo de estas páginas:

"[Amina] se despertó (...) como solía hacerlo en ese momento de cada noche..."27

"[Kamāal] se detuvo, como solía hacer todos los días a la misma hora..." 28

En realidad, estos primeros capítulos de la Trilogia narran una sola vez hechos y costumbres repetidos a diario, como la reunión del café, la vuelta de Kamāl de la escuela, el desayuno y la limpieza de la casa,

${ }^{25}$ Qāsim, S. A. Op. cit., p. 34.

${ }^{26}$ Op. cit., pp. 173-6.

${ }^{27}$ Mahfuz, N. E.P., p. 5.

${ }^{28}$ Ibid., p. 39. 
los golpes de la masa del pan, la salida de Yãsĩn y del señor a las tabernas y reuniones nocturnas...

Por lo que respecta a la temporalidad, esta frecuencia del relato iterativo empleada por Mahfüz en el exordio de Bayna l-Qaşrayn reduce el tiempo del relato, ya que cuenta una sola vez hechos que tienen lugar en la historia todos los días.

\subsubsection{Sucesividad/simultaneidad}

Como se ha mencionado anteriormente, este punto es propuesto por Bobes en su metodología del análisis textual. Según sus propias palabras, "el personaje vive sus acciones en sucesión en su tiempo vital, pero puede vivirlas en simultaneidad, anterioridad o posterioridad, por relación al tiempo de otro personaje" ${ }^{29}$.

En el exordio de Bayna l-Qașayn es de destacar que los seis primeros capítulos son continuación respectivamente de los anteriores -excluyendo lógicamente el primero-, es decir, los acontecimientos se van produciendo en sucesividad. Sin embargo, el capítulo 7 es simultáneo al 5 y al 6 , puesto que en aquél aparece el señor llegando a su tienda, mientras que en éstos, y a la vez, las mujeres de la casa desayunan e inician la limpieza de la casa. A continuación vuelve a producirse una sucesividad en los siguientes capítulos, rota en este caso porque el autor se dirige de nuevo hacia la tienda del señor, en el capítulo 14, cuando la "cámara", que ya ha recogido la salida de Yãsīn, se enfoca hacia dicha tienda para narrar las actividades del señor tras el cierre de ésta, en los capítulos 14 y 15, hechos que son a su vez simultáneos a los de Yāsīn, narrados en los capítulos 12 y 13 .

En este sentido, quiero resaltar el hecho de que en el exordio las simultaneidades se dan siempre en relación con el señor Ahmad, como si el autor quisiera no dejar tiempos en blanco en lo referente a este personaje, o como si su vida fuera independiente de la del resto de la familia y hubiera que narrarla por separado.

${ }^{29}$ Bobes Naves, M.C. Teoría general..., p. 154. 


\section{Conclusiones}

De este análisis de la estructura temporal en el exordio de Bayna l-Qaṣrayn pueden extraerse las siguientes conclusiones:

-El punto de partida de la obra deriva de una elección libre de su autor, que toma los acontecimientos en un punto cualquiera de la historia -no siendo en cualquier caso de especial relevancia, como sí ocurre con la elección de la fecha final de las tres obras- y a partir de ahí inicia la reconstrucción de los hechos.

-Naŷib Mahfüz transmite un ritmo de relato lento, incluso a veces detenido, logrado a través del uso de una serie se recursos a tal efecto, que ralentizan la exposición.

-Las pausas descriptivas detienen el tiempo del relato, pero son fundamentales para que el lector pueda conocer el pasado de los personajes.

-El uso de la memoria de los personajes, a través de monólogo o del estilo indirecto libre (retrospección subjetiva), junto con la narración del autor (retrospección objetiva), son los recursos fundamentales para reconstruir ese pasado.

-El relato de $\mathbf{2 4}$ horas de la vida de la familia 'Abd al-Ŷyawwād es novedoso respecto a la mayor parte de las obras realistas.

-El relato no sigue una línea ordenada, en la que los acontecimientos aparecen concatenados, sino que el autor oscila "entre el pasado y el presente, o sigue a cada uno de los personajes en su vida diaria, introduciendo al mismo tiempo en ella los elementos del pasado" ${ }^{130}$. Realiza aś un ágil movimiento de zigzag continuo entre el presente y el pasado.

-La analepsis es el recurso más utilizado a tal efecto por el autor, que de esa forma distingue claramente entre el "ahora" y el "antes" como segmentos puntuales de la historia, y los diferencia a su vez del "a menudo", que indica hechos repetidos del pasado al presente, y que hacen por tanto referencia a la cotidianeidad.

${ }^{30}$ Qāsim, S. A. Op. cit., p. 32. 
-Estas analepsis tienen en numerosas ocasiones un alcance muy amplio, es decir, se remontan a un pasado bastante alejado del momento del relato primero; o bien sitúan al lector en un tiempo inmediatamente anterior a ese relato primero.

-"Los elementos del pasado que Naŷib Mahfūz introduce en esta vida son de un tipo especial, pues son elementos repetidos desde el pasado al presente en forma de costumbres y de una rutina que se repite cada dra"31. De hecho se trata de una selección de motivos cotidianos, a los que el lector asiste sin que se produzca ni un solo acontecimiento digno de mención, que salga fuera de la rutina diaria. Todo lo que aparece recogido se ha producido en la vida de los personajes a lo largo de mucho tiempo, $\sin$ que se hayan dado cambios o novedades importantes; éstos vendrán después.

-Esa fijación en el pasado cotidiano o rutinario hace que no sea necesaria la puntualización temporal en el exordio. Por este motivo, y dado que se trata de hechos repetidos a lo largo de mucho tiempo, el autor no da una fecha exacta en ningún momento -como sí ocurrirá en otras partes de la Trilogia-, ni por lo que se refiere al día o al mes, ni siquiera a la estación o al año. Las únicas referencias orientativas son las menciones a la edad de los personajes, y ese dato tan repetido que nos dice que Amīna lleva un cuarto de siglo casada con el señor Ahmad. Sin embargo, ni unas ni otro son suficientes para situar al lector en la fecha en que se desarrolla el exordio. La situación vendrá esta vez de la mano de la historia externa al relato, ya que en el capítulo 2 se hace mención a un hecho histórico, dato que es suficiente para situar no sólo la época aproximada, sino incluso el día, mes y año en el que tiene lugar este primer día de la vida novelesca de los 'Abd al-Ŷawwād.

-Quiero aludir aqui a los evidentes paralelismos que se dan con los exordios de las restantes partes que componen la Trilogla -Qạ̣r al-Šawq y al-Sukkariyya-, aunque éstos ocupan mucho menos espacio en la novela, tres capítulos en el primer caso, uno solo en el segundo. Esta diferencia se debe a que el lector ya conoce una parte importante del

${ }^{31}$ Ibid., p. 32-33. 
pasado, y sólo tiene que ser informado de los acontecimientos ocurridos en los periodos que separan las obras entre sí.

-El análisis detallado de la temporalidad en el exordio de Bayna $l$ Qașrayn lleva a una última conclusión: se trata de la innegable maestría que demuestra Nayỉb Mahfüz en la utilización de los recursos que la cronologfa y la narrativa ponen a su alcance. Como bien apunta Bobes en su propuesta metodológica $-y$ considero que sus palabras son perfectamente aplicables a la Trilogia- "no todas las novelas resisten un análisis minucioso y detallado, porque muchas descubren que se limitan a lo superficial y anecdótico, pero las que son verdaderamente literarias muestran toda su riqueza semántica y hacen de la lectura literaria un placer estético e intelectual insospechado" ${ }^{32}$. Esta maestría de Mah̆ũz será confirmada en el resto de la Trilogía, demostrando por qué su autor considera que el tiempo es el principal protagonista de su obra, como ya se dijo al principio de este trabajo.

Para terminar este estudio sobre el tiempo en el exordio de Bayna l-Qașrayn, incluyo a continuación el análisis que hace Bajtin en su comentario a ciertos cronotropos de La Regenta, que considero recoge a la perfección, salvando las distancias, el espíritu que Naŷỉ Mạ̣füz quiso imprimir a la introducción de su Trilogía:

\footnotetext{
"Aquí no existen acontecimientos, sino, tan sólo, una repetición de lo 'corriente'. El tiempo carece aquí de curso histórico ascendente; se mueve en ciclos limitados: el ciclo del día, el de la semana, el de la vida entera. (...) Día tras día se repiten los mismos hechos corrientes, los mismos temas de conversación, las mismas palabras, etc. En ese tiempo, la gente come, bebe, tiene esposas, amantes (sin amor), intrigan mezquinamente, permanecen en sus tiendecitas y despachos, juegan a las cartas, chismorrean. Es el tiempo banal de la cíclica vida cotidiana..." ${ }^{133}$.
}

\footnotetext{
${ }^{32}$ Bobes Naves, M. C. Teoría general..., p. 10.

${ }^{33}$ Bajtin, M; Op. cit, p, 398.
} 